\title{
Bullae after rapid blood transfusion through a warming system
}

\author{
Kensuke Sakakibara, MD • Hiroyuki Kinoshita, MD, PhD • \\ Yoshihiro Fujiwara, MD, PhD
}

Received: 26 June 2012/ Accepted: 10 September 2012/Published online: 18 September 2012

(c) Canadian Anesthesiologists' Society 2012

\section{To the Editor,}

Level 1 blood and fluid warming systems, such as the Ranger $^{\mathrm{TM}}$ (Arizant Healthcare, Eden Prairie, MN, USA), are widely used to maintain normothermia in patients experiencing large-volume blood loss. ${ }^{1}$ Nevertheless, complications related to this type of device are not well known.

An 82-yr-old woman was scheduled for aortic and mitral valve replacement in combination with coronary artery bypass grafting. Informed consent to publish this report was obtained from the patient and her family on the first postoperative day. Before the induction of general anesthesia, a $20 \mathrm{G}$ catheter was inserted in her left forearm. We decided to use this catheter throughout the surgical procedure because cannulation of larger veins appeared impossible in her hand or upper extremity. During surgery, a second cardiopulmonary bypass was required to terminate massive hemorrhage from the right ventricle. Even after this procedure, extensive bleeding continued and resulted in severe hypotension with a systolic blood pressure of 50-60 mmHg. A Ranger fluid warming system was employed to avoid hypothermia induced by rapid transfusion into the 20G left peripheral venous line, which was covered by a drape during the operation. The infusion pressure is unknown because it was applied manually. The patient received $1,680 \mathrm{~mL}$ of red cell concentrates

K. Sakakibara, MD · H. Kinoshita, MD, PhD ( $\square)$.

Y. Fujiwara, MD, PhD

Aichi Medical University School of Medicine, Nagakute, Aichi, Japan

e-mail: hkinoshi@aichi-med-u.ac.jp (hematocrit 50-55\%) and 2,700 $\mathrm{mL}$ of fresh frozen plasma. Two hours after starting infusion of blood products, an anesthesiologist noticed that the peripheral venous line was blocked. At this time, purpura in combination with a number of transparent tense bullae more than $2 \mathrm{~cm}$ in diameter was observed in the patient's left forearm (Figure). The lesions were treated with ointment containing steroid for two days; unfortunately, we do not know the further outcome of the bullae because the patient died suddenly on the second postoperative day. It is likely that large-volume infusion causes extravasation of blood products and/or massive expansion of lymph vessels close to the skin, and this process may have produced a number of bullae in her left forearm. ${ }^{2}$ Several cases of bullous injury after rapid intravenous infusion have been reported, which suggests that the cause of skin lesions in our case was extravasation of infused fluids. ${ }^{3,4}$ All personnel involved in the clinical care of anesthetized patients should be aware of such a possible complication of rapid infusion of blood products when using any system under pressure.

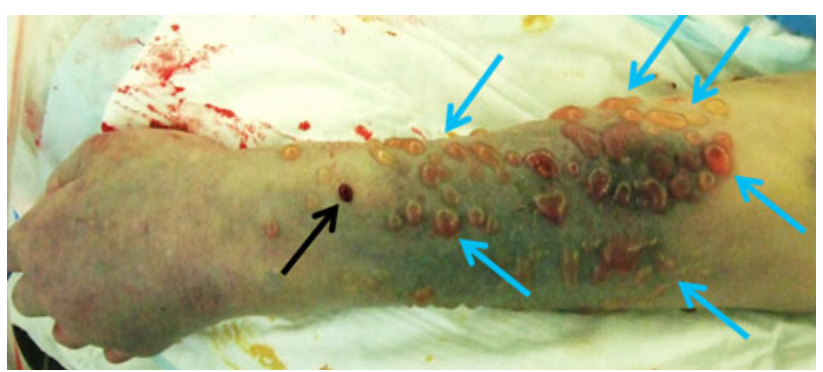

Figure Patient's left forearm. A number of transparent tense bullae (blue arrows) were detected in her left forearm two hours after starting infusion of blood products. The black arrow indicates the site where the peripheral venous catheter was inserted 
There is no convincing evidence that the problem was due to the particular blood infusion device used in this case.

Competing interests None declared.

\section{References}

1. Eaton MP, Dhillon AK. Relative performance of the level 1 and ranger pressure infusion devices. Anesth Analg 2003; 97: 1074-7.
2. Verma SB. Lymphangiectasias of the skin: victims of confusing nomenclature. Clin Exp Dermatol 2009; 34: 566-9.

3. Scholtes JL, Loriau E, Tombal B. Severe intraoperative acute compartment syndrome with bullous eruption complicating IV fluid administration. Anesth Analg 2006; 103: 783-4.

4. Panwar DD, Garz R, Goel SR, Choudhary A, Kaur MD, Pawar M. Gangrene of hand due to faulty intravenous cannulation: be cautious with hyperosmotic agents. J Anesthesiol Clin Pharmacol 2011; 27: 418-20. 